\title{
Spectroscopic and structural characterization of products arising from the base-promoted benzylation of 3-sulfolene
}

\author{
Muriel Bonnet, ${ }^{\text {a }}$ Martin G. Banwell,*a Anthony C. Willis, ${ }^{\text {a }}$ and Vito Ferro ${ }^{b}$ \\ ${ }^{a}$ Research School of Chemistry, Institute of Advanced Studies, The Australian National \\ University, Canberra, ACT 0200, Australia. \\ ${ }^{b}$ Drug Design Group, Progen Industries Ltd, 2806 Ipswich Road, Darra, QLD 4077, Australia \\ E-mail:
}

\begin{abstract}
Reaction of the title sulfone (1) with benzyl iodide at $-78^{\circ} \mathrm{C}$ in the presence of LiHMDS and using THF/DMPU as solvent affords a chromatographically separable mixture of the compounds 2-5 in a combined yield of $42 \%$. These products have been subjected to comprehensive spectroscopic characterization and the structures of products $\mathbf{2}$ and $\mathbf{5}$ established through singlecrystal X-ray analyses.
\end{abstract}

Keywords: Benzylation, 1,3-butadienes, fragmentation, 3-sulfolene

\section{Introduction}

In connection with a program directed towards the synthesis of cyclohexenyl-based antiangiogenic agents, ${ }^{1}$ we required access to a range of 1,4-dibenzylated and 1,1,4-tribenzylated1,3-butadienes posessing varying double-bond geometries. To that end we have investigated the reaction of commercially available 3-sulfolene (1) with benzyl iodide in the presence of lithium hexamethyldisilazide (LiHMDS) and in the expectation that, through control of reactant stoichiometry, the cis- and trans-2,5-dibenzyl- and/or 2,2,5-tribenzyl-3-sulfolenes, 2, 3 and 4 respectively, would be produced selectively. It was anticipated that thermolysis of these products would then deliver, through stereospecific cheleotropic extrusion of sulfur dioxide, the corresponding 1,3-butadienes that would serve as $4 \pi$-components in Diels-Alder cycloaddition reactions with appropriate dienophiles and so leading to the target cyclohexenes. This sort of approach to substituted 1,3-butadienes (and thence cyclohexenes) has been employed by various groups ${ }^{2}$ and even applied to the preparation of the required precursors $\mathbf{2}$ and $\mathbf{3}$ by Takayama and co-workers. ${ }^{3}$ However, the structures of the 2,5-dibenzylated products this group obtained were not rigorously established in so far as it was not absolutely clear that the major isomer possessed a trans-relationship between the two benzyl groups. Accordingly, we now detail the outcomes 
our own studies of the relevant reaction which has included the acquisition of a single-crystal Xray structure of compound 2 as well as that of one of the other three products obtained.

\section{Results and Discussion}

The benzylation of commercially available 3-sulfolene (1) was carried out at $-78^{\circ} \mathrm{C}$ in $\mathrm{THF}$ using benzyl iodide ${ }^{3}$ as electrophile and LiHMDS as base. Since the trans- and cis-2,5dibenzylated products, compounds 2 and 3 respectively, were deemed the most important of the possible products of reaction, two molar excesses of both the electrophile and base were employed. In addition, DMPU was used as co-solvent given the capacity of this polar aprotic species to facilitate alkylation reactions. Under such conditions four chromatographically separable products, 2-5, were obtained in a combined yield of 42\%. Despite the low yield involved, no other products of reaction were isolated and nor was any of the starting material recovered.

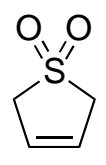

1

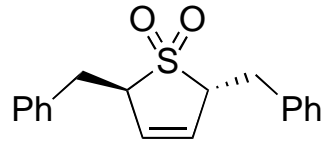

2

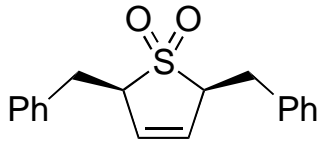

3
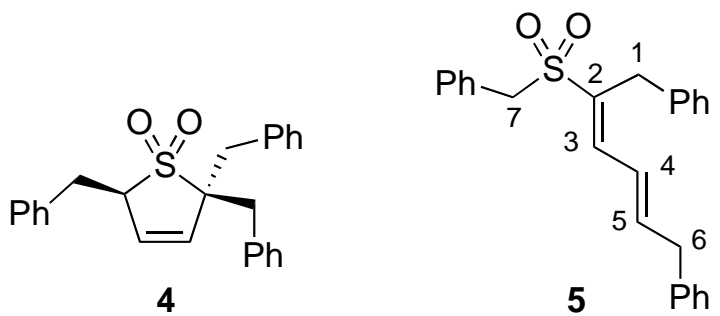

The major product of reaction (32\%) was one of the expected (and crystalline) 2,5dibenzylation products and this was accompanied by much lower yields (3\%) of its isomer. The spectral data obtained on these compounds matched those reported by Takayama. ${ }^{3}$ However, spectroscopic analysis of these materials did not permit unambiguous assignment of their structures since each possess symmetry elements $\left(C_{2}\right.$ vs $\left.C_{s}\right)$ that lead to very similar NMR spectra. For example, seven signals are seen in the ${ }^{13} \mathrm{C}$ NMR spectra of each of these compounds while there is remarkably little difference in the chemical shifts of the resonances arising from the benzylic and allylic protons in each of the isomers. Accordingly, the major and crystalline product of reaction was subjected to single crystal X-ray analysis (see Figure 1 and Experimental Section) and by such means it was established that this compound is the trans-isomer 2 . The predominance of this species over isomer $\mathbf{3}$ is not unexpected ${ }^{3}$ and presumably arises through the operation of kinetic and not thermodynamic effects since molecular mechanics calculations 
(OPLS-2003) indicate that the difference in ground-state energies of these cis- and trans-isomers is less than $1 \mathrm{~kJ} /$ mole. Thus, the mono-benzylated anion that serves as the common precursor to compounds $\mathbf{2}$ and $\mathbf{3}$ is expected, on steric grounds, to react with benzyl iodide such that the former product is formed more rapidly.

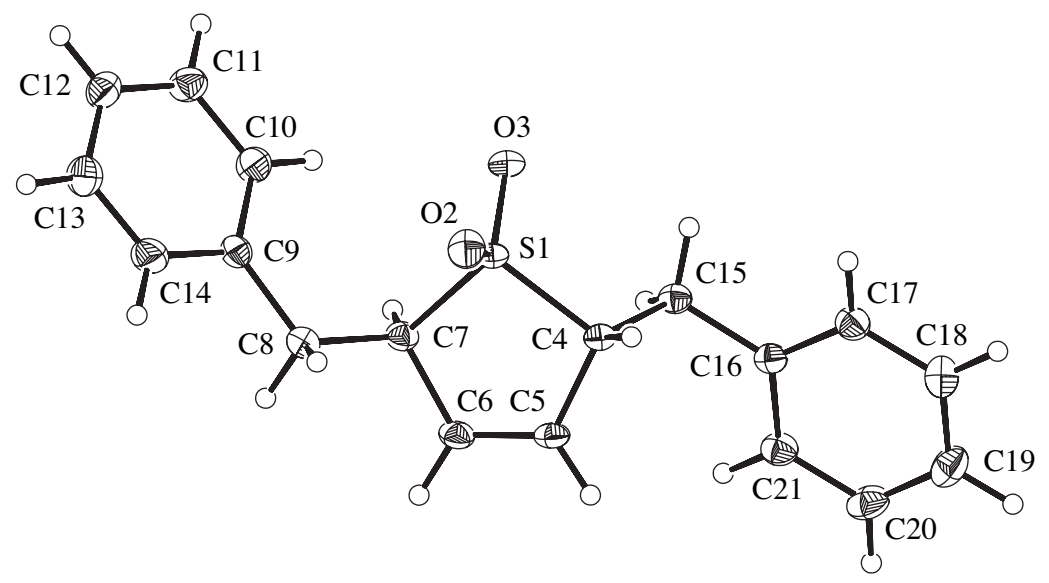

Figure 1. ORTEP derived from the single-crystal X-ray analysis of compound 2.

The spectral data derived from the tribenzylated product 4 , which was obtained in only $2 \%$ yield, were in full accord with the assigned structure. The analogous data derived from the fourth and final product, namely compound 5 (which was obtained in 5\% yield), clearly indicated the compound had incorporated three benzyl units while the presence of three olefinic protons suggested that the 3-sulfolene ring had been cleaved. Nevertheless, this product still incorporated a sulfone residue as evidenced by the appearance of diagnostic absorption bands at 1300, 1115 and $698 \mathrm{~cm}^{-1}$ in the infra-red spectrum. These and other spectroscopic properties led to the conclusion that product 5 possessed the illustrated structure but final confirmation of this followed from a single-crystal X-ray analysis, the outcomes of which are shown in Figure 2 as well as in the Experimental Section. This analysis reveals that both double-bonds possess the $E$ configuration. 


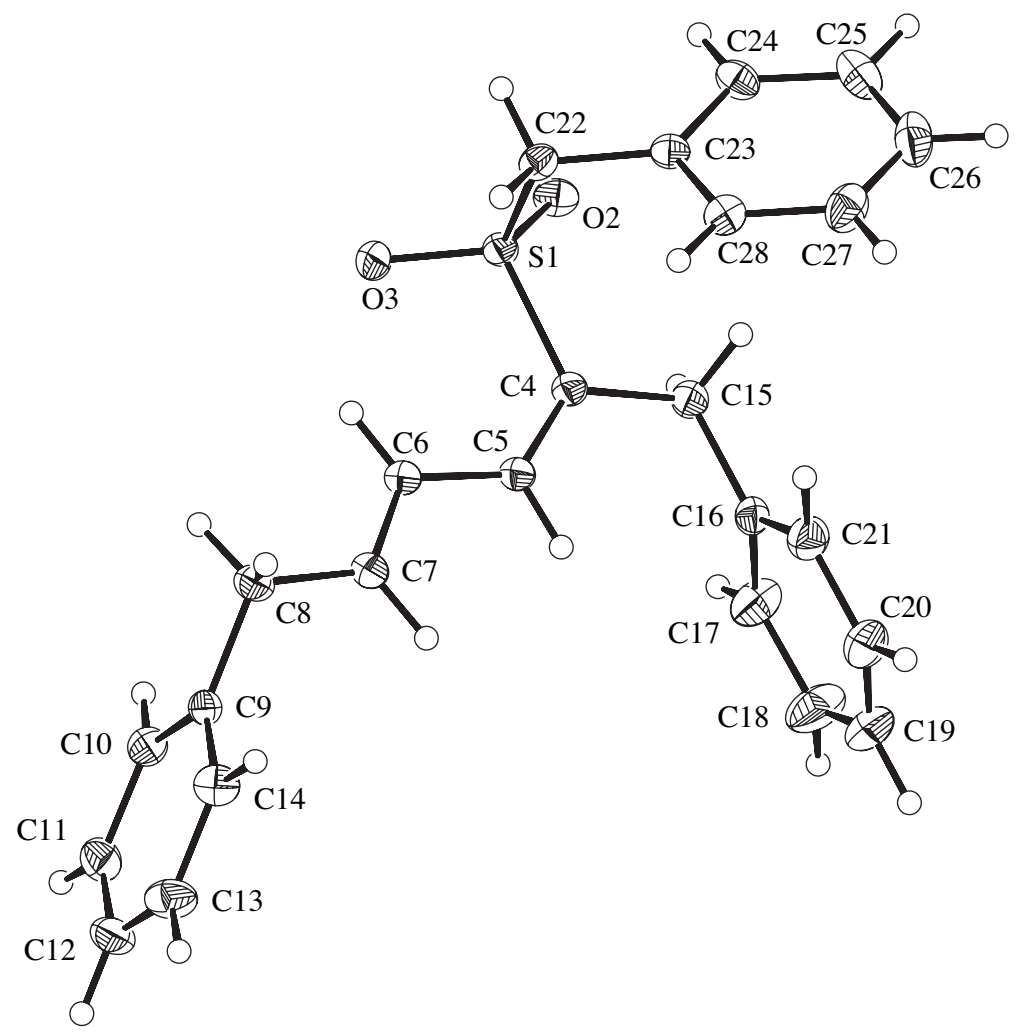

Figure 2. ORTEP derived from the single-crystal X-ray analysis of compound 5.

The formation of product 5 under the conditions described here is not unexpected since it is known that anions derived from 3-sulfolenes can undergo fragmentation to give sulfinate anions and that these, in turn, react with added electrophiles to give ring-opened sulfones. ${ }^{4}$ Thus, the anion derived from deprotonation of compound $\mathbf{2}$ and/or $\mathbf{3}$ presumably engages in the aforementioned fragmenation process and the resulting anion $\mathbf{6}$ is then benzylated, by the added electrophile, to give the observed product 5.<smiles>O=S(=O)([O-])/C(=C/C=C/Cc1ccccc1)Cc1ccccc1</smiles> 


\section{Experimental Section}

General Procedures. Spectral and physical data were recorded as detailed elsewhere. ${ }^{5}$ Medium pressure liquid chromatography was performed using a Versa Flash medium pressure system fitted with a SUPELCO Versa Pak $\mathrm{SiO}_{2}$ cartridge and operating at 65 psi while flash chromatography was conducted using protocols developed by Still et al. ${ }^{6}$

\section{Preparative studies}

Base-promoted Benzylation of 3-Sulfolene. Formation of trans-2,5-dibenzyl-3-sulfolene (2), cis-2,5-dibenzyl-3-sulfolene (3), 2,2,5-tribenzyl-3-sulfolene (4) and (2E,4E)-2(benzylsulfonyl)-1,6-diphenylhexa-2,4-diene (5). A magnetically stirred mixture of 3-sulfolene ( $2.0 \mathrm{~g}, 17 \mathrm{mmol})$, benzyl iodide $(4.3 \mathrm{~mL}, 34 \mathrm{mmol})$, and DMPU $(8.2 \mathrm{~mL}, 68 \mathrm{mmol})$ in anhydrous THF (120 mL) maintained at $-78^{\circ} \mathrm{C}$ under a nitrogen atmosphere was treated, dropwise, with LiHMDS (34 mL of a $1.0 \mathrm{M}$ solution in THF, $34 \mathrm{mmol}$ ). The ensuing mixture was stirred at $-78^{\circ} \mathrm{C}$ for $1 \mathrm{~h}$, quenched through addition of $\mathrm{NaCl}(50 \mathrm{~mL}$ of a saturated aqueous solution) then allowed to warm to $18^{\circ} \mathrm{C}$. The reaction mixture was extracted with $\mathrm{CH}_{2} \mathrm{Cl}_{2}(200 \mathrm{~mL})$ then diethyl ether $(3 \times 200 \mathrm{~mL})$. The combined organic extracts were dried $\left(\mathrm{MgSO}_{4}\right)$, filtered and concentrated under reduced pressure and the residue subjected to medium pressure chromatography $\left(\mathrm{SiO}_{2}, 5: 1 \mathrm{v} / \mathrm{v}\right.$ hexane/ethyl acetate elution) and thus affording four fractions, A-D.

Concentration of fraction $\mathrm{A}\left(R_{\mathrm{f}}=0.18\right)$ gave a white solid that was recrystallized (hexane/ethyl acetate) to afford trans-2,5-dibenzyl-3-sulfolene (2) ${ }^{3}(1.62 \mathrm{~g}, 32 \%)$ as colorless plates, $\mathrm{mp}=106-108^{\circ} \mathrm{C}\left[\right.$ Found $(\mathrm{M}+\mathrm{Na})^{+}$, 321.0924. $\mathrm{C}_{18} \mathrm{H}_{18} \mathrm{O}_{2} \mathrm{SNa}$ requires $(\mathrm{M}+\mathrm{Na})^{+}$, 321.0925]. ${ }^{1} \mathrm{H}$ NMR (300 MHz, $\mathrm{CDCl}_{3}$ ) $\delta$ 7.37-7.23 (complex m, 10H, ArCH), 5.90 (s, 2H, $\mathrm{CH}=\mathrm{CH}), 3.96\left(d d, J=5.4\right.$ and $\left.9.8 \mathrm{~Hz}, 2 \mathrm{H}, \mathrm{CH}-\mathrm{SO}_{2}\right), 3.43(d d, J=5.4$ and $13.9 \mathrm{~Hz}, 2 \mathrm{H}, \mathrm{CH}-$ $\mathrm{Ph}$ ), 2.83 (dd, $J=9.8$ and $13.9 \mathrm{~Hz}, 2 \mathrm{H}, \mathrm{CH}-\mathrm{Ph}) ;{ }^{13} \mathrm{C}$ NMR (75 MHz, $\left.\mathrm{CDCl}_{3}\right) \delta 136.4$ (s), 129.1 $(d), 128.8(d), 128.6(d), 127.1(d), 65.4(d), 34.7(t)$; IR (neat) $v_{\max } 3057 w, 3028 w, 2918 w$, $2847 w, 1602 w, 1495 m, 1454 m, 1303 s$ ( $\mathrm{SO}_{2}$ st as), 1219w, 1131s ( $\mathrm{SO}_{2}$ st sy), $1116 s$ ( $\mathrm{SO}_{2}$ st sy), $1077 w, 837 w, 731 m, 699 s$ (SO st), 637m, 477w; MS (ESI) m/z 619 [(2M + Na) $\left.{ }^{+}, 15 \%\right], 321$ [(M $\left.\left.+\mathrm{Na})^{+}, 100\right], 316\left[\left(\mathrm{M}+\mathrm{H}_{2} \mathrm{O}\right)\right]^{+}, 12\right], 257$ (12), 252 (6).

Concentration of fraction $\mathrm{B}\left(R_{\mathrm{f}}=0.15\right)$ gave a white solid that was subjected to flash chromatography (silica, 10:1 v/v hexane/ethyl acetate). Concentration of the relevant fractions $\left(R_{\mathrm{f}}=0.06\right)$ then gave cis-2,5-dibenzyl-3-sulfolene $(3)^{3}(162 \mathrm{mg}, 3 \%)$ as a clear, colorless oil [Found $(\mathrm{M}+\mathrm{Na})^{+}$, 321.0915. $\mathrm{C}_{18} \mathrm{H}_{18} \mathrm{O}_{2} \mathrm{SNa}$ requires $(\mathrm{M}+\mathrm{Na})^{+}$, 321.0925]. ${ }^{1} \mathrm{H} \mathrm{NMR}(300 \mathrm{MHz}$, $\left.\mathrm{CDCl}_{3}\right) \delta$ 7.38-7.23 (complex $\left.m, 10 \mathrm{H}, \mathrm{ArCH}\right), 5.89$ (s, 2H, $\left.\mathrm{CH}=\mathrm{CH}\right), 4.00(d d, J=5.8$ and 9.7 $\mathrm{Hz}, 2 \mathrm{H}, \mathrm{CH}-\mathrm{SO}_{2}$ ), 3.37 (dd, $J=5.8$ and $14.0 \mathrm{~Hz}, 2 \mathrm{H}, \mathrm{CH}-\mathrm{Ph}$ ), 2.75 (dd, $J=9.7$ and $14.0 \mathrm{~Hz}$, 2H, CH-Ph); ${ }^{13} \mathrm{C}$ NMR (75 MHz, $\left.\mathrm{CDCl}_{3}\right) \delta 136.4(s), 129.2(d), 128.9(d), 128.2(d), 127.2(d)$, $66.1(d), 34.8(t)$; IR (neat) $v_{\max } 3062 w, 3029 w, 2925 w, 2855 w, 1602 w, 1584 w, 1495 m, 1454 m$, 1304 s ( $\mathrm{SO}_{2}$ st as), 1226w, 1200w, 1133s ( $\mathrm{SO}_{2}$ st sy), 1111s ( $\mathrm{SO}_{2}$ st sy), 1077w, 1029w, 833w, 
728m, 700s (SO st), 639m, 588w, 557w, 514w, 483w; MS (ESI) m/z 619 [(2M + Na) $\left.{ }^{+}, 7 \%\right], 321$ [(M + Na) $\left.{ }^{+}, 100\right], 299\left[(\mathrm{M}+\mathrm{H})^{+}, 10\right], 257$ (31), 157 (41), 131 (12), 129 (10), 91 (20).

Concentration of fraction $\mathrm{C}\left(R_{\mathrm{f}}=0.33\right)$ gave a colorless oil that was subjected to flash chromatography (silica, 10:1 v/v hexane/ethyl acetate). Concentration of the relevant fractions $\left(R_{\mathrm{f}}=0.10\right)$ then gave 2,2,5-tribenzyl-3-sulfolene (4) (104 mg, 2\%) as a clear, colorless oil [Found $(\mathrm{M}+\mathrm{Na})^{+}$, 411.1398. $\mathrm{C}_{25} \mathrm{H}_{24} \mathrm{O}_{2} \mathrm{SNa}$ requires $\left.(\mathrm{M}+\mathrm{Na})^{+}, 411.1395\right] .{ }^{1} \mathrm{H} \mathrm{NMR}$ [300 $\mathrm{MHz}$, $\left.\left(\mathrm{CD}_{3}\right)_{2} \mathrm{CO}\right] \delta$ 7.38-7.15 (complex $\left.m, 15 \mathrm{H}, \mathrm{ArCH}\right), 6.08$ (dd, $J=2.5$ and $8.8 \mathrm{~Hz}, 1 \mathrm{H}, \mathrm{CH}=\mathrm{CH}$ ), $5.81(d d, J=2.3$ and $8.8 \mathrm{~Hz}, 1 \mathrm{H}, \mathrm{CH}=\mathrm{CH}), 3.43\left(m, 1 \mathrm{H}, \mathrm{CH}-\mathrm{SO}_{2}\right), 3.34(d, J=14.4 \mathrm{~Hz}, 1 \mathrm{H}$, $\mathrm{CH}-\mathrm{Ph}$ ), 3.17 ( $s, 2 \mathrm{H}, \mathrm{CH}-\mathrm{Ph}), 3.14$ (d, $J=14.4 \mathrm{~Hz}, 1 \mathrm{H}, \mathrm{CH}-\mathrm{Ph}), 3.03$ (dd, $J=7.0$ and $14.1 \mathrm{~Hz}$, $1 \mathrm{H}, \mathrm{CH}-\mathrm{CH}-\mathrm{Ph}), 2.44$ (dd, $J=8.7$ and $14.1 \mathrm{~Hz}, 1 \mathrm{H}, \mathrm{CH}-\mathrm{CH}-\mathrm{Ph}) ;{ }^{13} \mathrm{C}$ NMR $\left(75 \mathrm{MHz}, \mathrm{CDCl}_{3}\right.$ ) $\delta$ 136.5, 135.3, $135.2(3 \times s), 133.0(d), 131.5(d), 131.4(d), 129.0(d), 128.8(d), 128.4(d)$, $128.0(d), 127.3(d), 127.2(d), 127.1(d), 127.0(d), 71.8(s), 65.6(d), 40.1(t), 38.8(t), 32.9(t)$; IR (neat) $v_{\max } 3079 w, 3061 w, 3029 w, 2924 w, 1602 w, 1495 m, 1454 m, 1299 s\left(\mathrm{SO}_{2}\right.$ st as), $1128 \mathrm{~s}$ ( $\mathrm{SO}_{2}$ st sy), 1079w, 1030w, 733m, 699s (SO st), 630w, 580w, 521w, 485w; MS (ESI) m/z 501 (4\%), 412/411 [(M + Na $\left.)^{+}, 26 / 85\right], 406\left[\left(\mathrm{M}+\mathrm{H}_{2} \mathrm{O}\right)^{+}, 27\right], 389\left[(\mathrm{M}+\mathrm{H})^{+}, 10\right], 348(17), 347$ (62), 221 (56), 129 (31), 117 (72), 91 (100).

Concentration of fraction $\mathrm{D}\left(R_{\mathrm{f}}=0.22\right)$ afforded a white solid that was recrystallized $\left(\mathrm{CH}_{2} \mathrm{Cl}_{2}\right.$ /hexane/ethyl acetate) to give (2E,4E)-2-(benzylsulfonyl)-1,6-diphenylhexa-2,4-diene (5) (315 mg, 5\%) as colorless needles, $\mathrm{mp}=137-139^{\circ} \mathrm{C}\left[\right.$ Found $(\mathrm{M}+\mathrm{H})^{+}$, 389.1578. $\mathrm{C}_{25} \mathrm{H}_{25} \mathrm{O}_{2} \mathrm{~S}$ requires $(\mathrm{M}+\mathrm{H})^{+}$, 389.1575]. ${ }^{1} \mathrm{H} \mathrm{NMR}\left(300 \mathrm{MHz}, \mathrm{CDCl}_{3}\right) \delta 7.34-7.07$ (complex m, 15H, $\operatorname{ArCH}), 6.62$ (dd, $J=11.1$ and $15 \mathrm{~Hz}, 1 \mathrm{H}, \mathrm{H} 4), 6.34$ (d, $J=11.1 \mathrm{~Hz}, 1 \mathrm{H}, \mathrm{H} 3), 5.90$ (dt, $J=7.3$ and $15 \mathrm{~Hz}, 1 \mathrm{H}, \mathrm{H} 5), 3.94$ (s, 2H, H7), 3.53 (s, 2H, H1), 3.33 (d, J = 7.3 Hz, 2H, H6) ; ${ }^{13} \mathrm{C}$ NMR $\left(75 \mathrm{MHz}, \mathrm{CDCl}_{3}\right) \delta 143.8(d), 142.0(d), 138.9(s), 137.0(s), 135.2(s), 131.2(d), 129.7(d)$, 128.9(3) (d), 128.8(8) (d), $128.7(d, 3 \times \mathrm{C}), 127.9(s), 127.2(s), 126.6(s), 125.7(s), 62.3(t), 39.9$ $(t), 39.4(t)$; IR (neat) $v_{\max } 3062 w, 3028 w, 2917 w, 2847 w, 1635 m, 1602 m, 1494 m, 1454 m$, $1428 w, 1300 s$ ( $\mathrm{SO}_{2}$ st as), 1254w, 1143m, 1115s ( $\mathrm{SO}_{2}$ st sy), 1075w, 1029w, 980w, 918w, 875w, $787 w, 731 w, 698 s$ (SO st), 635w, 543w, 528w; MS (ESI) m/z 799 [(2M + Na) $\left.{ }^{+}, 13 \%\right], 411$ [(M + $\left.\mathrm{Na})^{+}, 22\right], 406$ [(M + $\left.\left.\mathrm{H}_{2} \mathrm{O}\right)^{+}, 13\right], 389$ [(M+ H) $\left.{ }^{+}, 100\right], 233$ (8), 179 (6), 157 (6), 117 (6), 91 (24).

\section{Crystallographic studies}

Crystal data (for compound 2). $\mathrm{C}_{18} \mathrm{H}_{18} \mathrm{O}_{2} \mathrm{~S}, M=298.41, T=200(1) \mathrm{K}$, monoclinic, space group $P 2{ }_{1} / \mathrm{a}, Z=4, a=13.4736(2), b=8.1277(1), c=14.8515(3) \AA, \beta=112.7440(2)^{\circ}, V=$ 1499.91(4) $\AA^{3}, D_{x}=1.321$ g. $\mathrm{cm}^{-3}, 3441$ unique data $\left(2 \theta_{\max }=55^{\circ}\right)$, 2438 with $I>3.0 \sigma(I) ; R=$ $0.0282, R w=0.0328, S=1.0951$.

Crystal data (for compound 5). $\mathrm{C}_{25} \mathrm{H}_{24} \mathrm{O}_{2} \mathrm{~S}, M=388.53, T=200(1) \mathrm{K}$, monoclinic, space group $P 2{ }_{1} / c, Z=4, a=13.5805(2), b=5.6410(1), c=27.5011(5) \AA, \beta=100.9472(7)^{\circ}, V=$ 2068.46(6) $\AA^{3}, D_{x}=1.248$ g.cm $\mathrm{cm}^{-3}, 4725$ unique data $\left(2 \theta_{\max }=55^{\circ}\right)$, 2993 with $I>3.0 \sigma(I) ; R=$ $0.0278, R w=0.0344, S=1.1111$.

Structure determination. Images were measured on a Nonius Kappa CCD diffractometer (MoK $\alpha$, graphite monochromator, $\lambda=0.71073 \AA$ ) and data extracted using the DENZO 
package. ${ }^{7}$ Structure solution was by direct methods (SIR92). ${ }^{8}$ The structures of compounds 2 and 5 were refined using the CRYSTALS program package. ${ }^{9}$ Atomic coordinates, bond lengths and angles, and displacement parameters have been deposited at the Cambridge Crystallographic Data Centre (CCDC reference numbers for compounds 2 and 5, 284578 and 284681 repectively). These data can be obtained free-of-charge via http://www.ccdc.cam.ac.uk/data_request/cif, by emailing data_request@ccdc.cam.ac.uk, or by contacting The Cambridge Crystallographic Data Centre, 12, Union Road, Cambridge CB2 1EZ, UK; fax: +44 1223336033.

\section{Acknowledgements}

We gratefully acknowledge Progen Industries Ltd (Brisbane) for financial support and Dr Andreas Kreipl for conducting some preliminary experiments. Dr Ian Bytheway is warmly thanked for carrying out molecular mechanics calculations on compounds $\mathbf{2}$ and $\mathbf{3}$.

\section{References and Footnotes}

1. Banwell, M. G.; Bissember, A.; Bonnet, M.; Kreipl, A.; Renner, J.; Willis, A. C.; Ferro, V. to be submitted.

2. For a review of much of the pivotal work in this area see: Chou, T. S.; Tso, H. H. Org. Prep. Proceed. Int. 1989, 21, 257. For specific studies on the one-pot multialkylation reactions of 3-sulfolene see: Chou, T. S.; Chong, L. J.; Tso, H. H. J. Chem. Soc., Perkin Trans. 1 1986, 1039.

3. Yamada, S.; Ohsawa, H.; Suzuki, T.; Takayama, H. J. Org. Chem. 1986, 51, 4934.

4. Chou, T. S.; Chang, S. Y. J. Org. Chem. 1992, 57, 5015 and references cited therein.

5. Banwell, M. G.; Loong, D. T. J.; Willis, A. C. Aust. J. Chem. 2005, 58, 511.

6. Still, W.C.; Kahn, M.; Mitra, A. J. Org. Chem. 1978, 43, 2923.

7. DENZO-SMN. Otwinowski, Z.; Minor, W. Processing of X-ray diffraction data collected in oscillation mode. In Methods in Enzymology, Volume 276: Macromolecular Crystallography, Part A; Carter Jr., C. W.; Sweet, R. M., Eds.; Academic Press: New York, 1997; pp. 307-326.

8. Altomare, A.; Cascarano, G.; Giacovazzo, C.; Guagliardi, A.; Burla, M. C.; Polidori, G.; Camalli, M. J. Appl. Crystallogr. 1994, 27, 435.

9. Betteridge, P. W.; Carruthers, J. R.; Cooper, R. I.; Prout, K.; Watkin, D. J. J. Appl. Crystallogr. 2003, 36, 1487. 